\title{
COVID-19 in severe asthma treated with omalizumab: The Maltese perspective
}

\author{
Nicole Sciberras ${ }^{1}$, Caroline Gouder ${ }^{2}$, Stephen Montefort ${ }^{2}$
}

\begin{abstract}
INTRODUCTION SARS-CoV-2 was identified as the causative agent of the COVID-19 pandemic, which has been the focus of extensive research for over a year. Asthmatics were listed as a high-risk group for susceptibility to SARSCoV-2. Several hypotheses have been proposed regarding protective factors in asthmatics, amongst which were the role of biological agents. One such agent is omalizumab, an IgE inhibitor, which is currently the only biological agent available in Malta for the treatment of severe asthma.

METHODS This study aims to evaluate the symptomatology and disease course of SARS-CoV-2 in our cohort of severe asthmatic patients on omalizumab that contracted COVID-19. Molecular diagnostic tests (SARSCoV-2 PCR tests taken, if any, and the PCR result) since March 2020 of all adult patients receiving omalizumab for severe allergic asthma in January 2021, were reviewed from I-soft Clinical Manager ${ }^{\circledR}$. Demographic data were collected for those patients who were found to be positive.

RESULTS Our cohort included 58 patients, of whom 43 had PCR tests. Of these, 7 patients (12\%) tested positive during the study period. Results show a male predominance in the cohort, with fever being the commonest symptom, and a mortality of only 1 patient out of 7 .

CONCLUSIONS From the small number of our severe asthmatic patients infected with SARS-CoV-2 whilst receiving omalizumab, the majority had only mild symptoms, with minimal effect on asthma-related symptoms and hospitalizations, apart from mortality in one patient.
\end{abstract}

\author{
AFFILIATION \\ 1 Department of Medicine, Mater Dei \\ Hospital, Msida, Malta \\ 2 Department of Respiratory Medicine, Mater \\ Dei Hospital, Msida, Malta
}

\section{CORRESPONDENCE TO}

Nicole Sciberras. Department of Medicine, Mater Dei Hospital, MSD 2090, Msida, Malta. E-mail: nikk_scib@hotmail.com

\section{KEYWORDS}

SARS-CoV-2, severe asthma, COVID-19, omalizumab, corticosteroids

Received: 28 May 2021

Revised: 31 July 2021

Accepted: 25 August 2021

\section{INTRODUCTION}

The severe acute respiratory syndrome coronavirus 2 (SARS-CoV-2) has been identified as the causative agent of the COVID-19 pandemic, which has been the focus of news portals and extensive research for over a year ${ }^{1}$. Several studies aimed to establish the prognostic factors in patients diagnosed with SARS-CoV-2, including the impact of pre-existing lung disease such as asthma. Asthmatics were initially listed as a high risk group for susceptibility to SARS-CoV-2, but asthma prevalence amongst SARSCoV-2 patients was found to be low. Whether this is due to underdiagnosis of chronic respiratory diseases, a protective effect of chronic respiratory diseases, asthmatics being overcautious, or a protective effect of treatment used to control respiratory conditions remains unclear².

A number of hypotheses have been postulated concerning atopic asthmatics' potential protective effect from SARSCoV-2. This is in view of a reduced number of angiotensin converting enzyme-2 (ACE-2) receptors in this cohort of patients. ACE-2 receptors are expressed on nasal, lung, cardiac and intestinal epithelium, and one of the virus's constituents, the spike protein, aids entry of SARS-CoV-2 into the host cell through this receptor. This process is enhanced by endosomal proteases and the Furin protein.
It thus follows that a reduced number of ACE-2 receptors confers a protective effect in asthmatics ${ }^{3}$. This protective effect is further augmented by decreased Furin expression and increased ADAM-17 expression in asthmatics ${ }^{4}$. ACE2 receptors are also downregulated in patients on inhaled corticosteroids ${ }^{5}$. These mechanisms have been hypothesized to be the potential reason why asthma prevalence is lower in patients hospitalized due to SARS-CoV-2, in contrast to what occurred with other viral infections such as influenza6.

Severe asthma is defined by the Global Initiative for Asthma as uncontrolled asthma despite treatment optimization and patient management as per guidelines, that is, patients are still symptomatic or experiencing exacerbations whilst treated with high-dose inhaled corticosteroids and other medications which may include oral corticosteroids. Biological therapy plays an important role to achieve asthma control in selected patients ${ }^{7}$. Severe asthma results in increased utilization of healthcare resources, amongst which are intensive therapy unit stays ${ }^{8}$.

In light of the above, our study is the first of its kind locally, and attempts to explore the relationship between SARS-CoV-2 and asthmatic patients on biological therapy. It highlights a low prevalence of SARS-CoV-2 amongst patients with severe asthma on omalizumab. Whilst the 
majority of patients did experience symptoms, less than half of the patients were hospitalized, one of which died whilst hospitalized.

The aim of this study was to describe the impact of COVID-19 infection on Maltese patients receiving omalizumab for IgE-mediated severe allergic asthma, the only biological agent available for asthma since the start of the pandemic in Malta.

\section{METHODS}

Molecular diagnostic tests (SARS-CoV-2 PCR tests taken, if any, and the PCR result) since March 2020 of all adult patients receiving omalizumab for severe allergic asthma in
January 2021, were reviewed from I-soft Clinical Manager ${ }^{\circledR}$. Patients receiving omalizumab in Malta had consented in writing prior to starting treatment and all agreed to participate in any observational study throughout the duration of treatment. Verbal consent was then obtained for this study. Patients were contacted and verbally consented to participate in this study if the PCR result was positive. Demographic data were collected for those patients who were swabbed positive, including age and gender, as well as duration of treatment with omalizumab, number of swabs taken, date of symptom onset (if any), nature and duration of symptoms, any hospitalization whilst SARS-CoV-2 positive, any residual symptoms following negative PCR, date of

Table 1. Demographic data of patients receiving omalizumab who tested positive for COVID-19

\begin{tabular}{l|c|c|c|c|c}
$\begin{array}{l}\text { Patient } \\
\text { No. }\end{array}$ & $\begin{array}{c}\text { Age } \\
\text { (years) }\end{array}$ & Gender & $\begin{array}{c}\text { Duration of omalizumab } \\
\text { treatment (years) }\end{array}$ & $\begin{array}{c}\text { Systemic corticosteroids } \\
\text { on testing positive }\end{array}$ & \multicolumn{1}{c}{ Co-morbidities } \\
\hline 1 & 72 & Male & 5 & No & $\begin{array}{l}\text { Obesity, hypertension, congestive } \\
\text { heart failure }\end{array}$ \\
\hline 2 & 40 & Male & 8 & No & None \\
\hline 3 & 29 & Female & 1 & No & Diabetes mellitus, hypertension, \\
\hline 4 & 56 & Male & 8 & No & hyperlipidemia \\
\hline 5 & 31 & Male & 3 & No & Nonesity \\
\hline 6 & 65 & Male & 9 & No & Hypertension, gastro-oesophageal \\
7 & 59 & Male & 4 & & reflux, obesity, bronchiectasis
\end{tabular}

Table 2. Symptoms of COVID-19 infection

\begin{tabular}{|c|c|c|c|c|c|c|c|c|c|}
\hline $\begin{array}{l}\text { Patient } \\
\text { No. }\end{array}$ & $\begin{array}{l}\text { COVID-19 } \\
\text { symptoms }\end{array}$ & $\begin{array}{r}\text { Cc } \\
\text { sy } \\
\text { (res) }\end{array}$ & $\begin{array}{l}\text { OVID-19 } \\
\text { mptoms } \\
\text { piratory vs } \\
\text { other ) }\end{array}$ & $\begin{array}{l}\text { Duration } \\
\text { of } \\
\text { symptoms } \\
\text { (days) }\end{array}$ & Hospitalization & $\begin{array}{c}\text { Invasive } \\
\text { ventilation }\end{array}$ & $\begin{array}{c}\text { Asthma } \\
\text { worsening }\end{array}$ & $\begin{array}{l}\text { Asthma } \\
\text { treatment } \\
\text { increased }\end{array}$ & $\begin{array}{l}\text { Mortality } \\
\text { whilst } \\
\text { COVID-19 } \\
\text { positive }\end{array}$ \\
\hline 1 & Yes & $\begin{array}{l}\text { Dry } \\
\text { cough }\end{array}$ & - & 7 & No & No & No & No & No \\
\hline 2 & Yes & - & Fever & 2 & No & No & No & No & No \\
\hline 3 & Yes & - & $\begin{array}{l}\text { Fever, } \\
\text { headache, } \\
\text { anosmia, } \\
\text { ageusia }\end{array}$ & 10 & No & No & No & No & No \\
\hline 4 & Yes & $\begin{array}{l}\text { SOB, } \\
\text { chest } \\
\text { pain }\end{array}$ & $\begin{array}{l}\text { Dizziness, } \\
\text { fever, } \\
\text { diarrhea }\end{array}$ & $\begin{array}{c}4 \text { (then } \\
\text { intubated) }\end{array}$ & Yes & Yes & No & No & Yes \\
\hline 5 & Yes & SOB & Sore throat & 13 & Yes, 1 day & No & Yes & Yes & No \\
\hline 6 & No & - & - & - & No & No & No & No & No \\
\hline 7 & Yes & - & $\begin{array}{l}\text { Myalgia, } \\
\text { fever, } \\
\text { prostatism, } \\
\text { malaise }\end{array}$ & 17 & Yes, 1 day & No & No & No & No \\
\hline
\end{tabular}

SOB: shortness of breath. 
swab (positive and negative) as well as any interference with omalizumab treatment. Ethical approval from the local ethics board was granted to access patient data for the demographic data required for the study.

\section{RESULTS}

Our cohort of patients on omalizumab comprised 58 patients; 30 males and 28 females. The youngest patient was 18 years old whilst the oldest was 75 years old. Duration of treatment with omalizumab varied, with the largest proportion of patients initiating treatment in 2012; this was the year omalizumab was introduced in Malta. A total of 43 patients had performed PCR tests at least once between March 2020 and January 2021. Of these, 7 patients (12\%) were tested positive during the study period. Table 1 shows the demographic data of patients who tested positive for COVID-19. The majority of patients were male (85.7\%) and the mean age was $50.30 \pm 16.97$ years. Table 2 shows the impact of COVID-19 infection on their health with a focus on respiratory symptoms. All patients did not receive omalizumab during the infective period since patients could not attend the hospital, where treatment is received regularly. In Malta at the time of writing, self-administration of omalizumab was not approved. We could not identify any discriminating demographic factors to explain why these seven patients on omalizumab became infected with SARSCoV-2.

The most common symptom was fever in $57.1 \%$. The mean duration of symptoms was $7.60 \pm 5.64$ days. One patient passed away while suffering from COVID-19 infection complications after 12 days since testing positive. He was intubated after one day of hospitalization in view of severe respiratory failure secondary to SARS-CoV-2 pneumonia confirmed on radiological imaging. He was never wheezy.

\section{DISCUSSION}

In Malta, omalizumab is the only biological therapy available on the national formulary for severe asthma, and thus comparative studies about SARS-CoV-2 impact with other biological therapies are not possible. The results highlight that, in Malta, a low prevalence of SARS-CoV-2 was observed amongst patients with severe asthma treated with omalizumab, despite a high testing rate. This is in keeping with studies concerning patients with severe asthma on biological therapy.

Local cumulative statistics until the last day of data collection (31 January 2021) reported a total of 17903 cases since the start of the pandemic, of which 2676 were active cases at the time. There were 267 deaths in total, including the one patient in our study. Incidence during January 2021 was over 100 new cases daily.

Fever was the commonest symptom of SARS-CoV-2 of which the patients complained. One patient remained asymptomatic throughout being positive, and had been tested due to contact with a relative who had been diagnosed earlier with COVID-19. The results show that less than half of severe asthmatics diagnosed with SARS-CoV-2 required hospitalization. None of the severe asthmatics without other comorbidities required hospitalization. The patient who died whilst hospitalized and intubated due to SARS-CoV-2 pneumonia was the only one from the cohort who was also a known case of diabetes mellitus. Following several initial reports of diabetes being a prognostic factor for progression of SARS-CoV-2, this might explain the morbidity experience in this case?

Initially, patients with chronic lung disease were enlisted as a high risk group, based on the presumption that viral infections may exacerbate respiratory diseases ${ }^{10}$. The US Centers for Disease Control and Prevention stated that "people with moderate to severe asthma may be at higher risk of getting very sick from COVID-19. COVID-19 can affect your respiratory tract (nose, throat, lungs), cause an asthma attack and possibly lead to pneumonia and acute respiratory disease' ${ }^{\prime 1}$. Chronic obstructive pulmonary disease has in fact been linked to severe SARS-CoV-2 ${ }^{12}$.

However, reports emerging from Wuhan, the city of origin of SARS-CoV-2, showed a low prevalence of asthma in patients affected by SARS-CoV-2 ${ }^{13}$. One may argue that this may be the case due to underdiagnosis of asthma in China ${ }^{14}$, yet several other countries shared similar results, these include Russia, Saudi Arabia, Brazil, Sweden and Italy. This is in sharp contrast to Spain and Ireland, where asthma prevailed in $5.2 \%$ and $8.8 \%$, respectively, in patients infected with SARS-CoV-2 ${ }^{15}$. Broadhurst et al. ${ }^{16}$ also pointed out that asthma prevalence amongst hospitalized SARS-CoV-2 patients is lower than amongst those with influenza ${ }^{16}$.

However, as the Allergic Rhinitis and its Impact on Asthma - European Academy of Allergy and Clinical Immunology (ARIA-EAACI) statement points out, it is difficult to obtain statistics on asthma prevalence on SARS-CoV-2, as the patients may be elderly or have multiple other underlying health conditions. These data are sometimes not available or not specified in studies, and thus susceptibility of asthmatics to SARS-CoV-2 may be obscure. The risk of contracting SARS-CoV-2 may also be related to age, genetic predisposition, ethnicity, social behavior, and comorbidities ${ }^{17}$.

Data on the prevalence of asthma among hospitalized patients suffering from COVID-19 infection has not been analyzed yet in Malta. On an international level, Izquierdo et al. ${ }^{18}$ point out that patients with COVID-19 and asthma were of older age, female predominance, comorbid and with smoking tendency, when compared to the cohort of asthmatic patients without COVID-19. The Beurnier et al. ${ }^{19}$ study results on the characteristics of asthmatic patients with SARS-CoV-2 pneumonia were in concordance with the Izquierdo et al. ${ }^{18}$ study, concluding that asthmatics are not overrepresented in terms of hospitalization and adverse outcomes from pneumonia, but comorbidities do contribute towards morbidity and mortality ${ }^{19}$. Whilst inhaled corticosteroids have been deemed protective against SARS- 
CoV-2, recent use of oral corticosteroids was identified as a risk factor for SARS-CoV-2 related death ${ }^{20}$.

Another aspect of the relationship between asthma and SARS-CoV-2 is whether asthmatics are at an increased risk of severe SARS-CoV-2. Studies carried out in Saudi Arabia, Brazil and Spain reported a lower prevalence of moderate to severe asthma in severe SARS-CoV-2 when compared to cases of mild SARS-CoV-2 $21-23$. In Italy, asthma did not feature as a comorbidity associated with a higher mortality risk from SARS-CoV-2 ${ }^{24}$. Similarly, a small Swiss study reported a $4 \%$ prevalence of asthma amongst hospitalized SARS-CoV-2 patients ${ }^{25}$. These data have not yet been extrapolated locally.

A further question that arises is whether asthmatics are at increased risk of death from SARS-CoV-2. A cohort study conducted by Williamson et al. ${ }^{20}$ in the UK, using primary health electronic health records, did report an increased risk of death in asthmatic patients, especially those on high dose inhaled corticosteroids, implying these patients are severe asthmatics. However, several other factors including age were noted to play a role in mortality from SARS-CoV- $2^{20}$. On the other hand, the Bloom et al. ${ }^{26}$ study concludes that the use of inhaled corticosteroids within 2 weeks of admission, improves survival for patients aged 50 years and older with asthma.

The first report of SARS-CoV-2 in patients with severe asthma was from Spain, and concerned two patients on benralizumab. Both patients were aged over 50 years and had been diagnosed with eosinophilic asthma together with bronchiectasis. Both presented with fever and increased sputum, had SARS-CoV-2 pneumonia findings on their chest $X$-rays and were treated with antibiotics. They both recovered uneventfully at home despite initially presenting to hospital ${ }^{27}$.

Renner et al. ${ }^{28}$ report a case of a male aged 41 years whose eosinophilic asthma was well controlled on benralizumab started two years previously, who developed a high fever in March 2020 and tested positive for SARSCoV-2. His symptoms subsided within a few days and despite a moderate deterioration in asthma control during the infective period, his asthma control test did not show an overall decline in the long-term ${ }^{28}$.

Another reported case involved a German male, also aged over 50 years, who was confirmed positive for SARSCoV-2 via PCR test following a skiing trip in Austria. He had suffered from early-onset allergic asthma treated with omalizumab in view of recurrent exacerbations on maximal asthma treatment. He did not have other comorbidities and also made a good recovery at home, without the use of short acting B2-agonist use, and omalizumab was selfadministered with only a two-day delay ${ }^{29}$.

A case report originating from Turkey concerns a female aged 54 years who died of SARS-CoV-2. She was a known diabetic, severe asthmatic on omalizumab, obese and also suffered from familial Mediterranean fever. She presented in a hypoxic state and a pneumonia typical of SARS-CoV-2 was evident on high resolution CT thorax, which was treated using hydroxychloroquine and dexamethasone. Despite intubation, the patient suffered multi-organ failure and passed away on the fourteenth day post-admission to intensive care unit ${ }^{8}$.

On a larger scale, the results from the Italian Severe Asthma Registry (IRSA) were also in keeping with the proposition that biological therapies do not increase the risk of morbidity and mortality with SARS-CoV-2. Firstly, the study noted that hospitalization rate in severe asthma patients with SARS-CoV-2 was not significantly different in comparison with the general population, and neither was the median length of stay in hospital. No intensive care unit admissions were reported. Secondly, treatment with biological therapy, compared to inhaled corticosteroids - long acting beta agonist (ICS-LABA) alone, did not increase the risk of SARS-CoV-2 infection ${ }^{30}$.

The Belgian Severe Asthma Registry data are in keeping with the latter finding, however one must note that from a total of 676 patients, 66 underwent PCR testing with only 9 confirmed SARS-CoV-2 cases. The same study found that none of the 58 patients on maintenance oral corticosteroids was infected with SARS-CoV-2 ${ }^{31}$.

In Spain, 545 patients from the Spanish Network of Asthma with severe asthma on biological therapy were studied between March and June 2020, where a total of 35 patients were diagnosed with SARS-CoV-2, 17 of which by PCR and 18 based on symptomology and antibody testing; 7 patients required hospital admission, 5 patients due to pneumonia and 2 in view of severity of SARS-CoV-2, one of whom died in hospital. On comparison of this cohort to the characteristics of SARS-CoV-2 patients hospitalized throughout Spain, no difference was found in terms of severity of SARS-CoV-2, morbidity and mortality ${ }^{32}$. Another Spanish study of 80 patients with severe asthma observed that 3 patients were confirmed to be SARS-CoV-2 positive, with a bilateral pneumonia in two cases. None of them developed severe symptoms, or required ITU admission. Furthermore, severe asthmatics on biological therapy in this study did not have increased asthma exacerbations due to SARS- CoV-2 infection ${ }^{33}$.

In light of all this, Abdelmaksoud et al. ${ }^{34}$ propose researching the use of omalizumab as treatment for SARS-CoV-2 based on the Wang et al. ${ }^{35}$ study of mice receiving an intramuscular injection of omalizumab-small peptide segment. The latter could inhibit synthesis of proinflammatory cytokines which activate nuclear factor kappa B responsible for acute lung injury in SARS-CoV-2.

\section{Limitations}

The limitations of our study include the small cohort of patients, though exhaustive of the Maltese population receiving omalizumab, until completion of the study date. In addition, the study was retrospective so information recalled by patients may not be accurate, although data were collected in less than a year from the time of infection. 


\section{CONCLUSIONS}

From the small number of our severe asthmatic patients infected with SARS-CoV-2 whilst receiving omalizumab, the majority had only mild symptoms, with minimal effect on asthma- related symptoms and no asthma-related hospitalizations, apart from mortality in one patient. Further large-scale studies are required to evaluate the effect of omalizumab on SARS-CoV-2 infection via the pathways described above.

\section{CONFLICTS OF INTEREST}

The authors have completed and submitted the ICMJE Form for Disclosure of Potential Conflicts of Interest and none was reported.

\section{FUNDING}

There was no source of funding for this research.

\section{ETHICAL APPROVAL AND INFORMED CONSENT}

Ethical approval from the local ethics board was granted to access patient data for the demographic data required.

\section{DATA AVAILABILITY}

The data supporting this research are available from the authors on reasonable request.

\section{PROVENANCE AND PEER REVIEW}

Not commissioned; externally peer reviewed.

\section{REFERENCES}

1. World Health Organization. COVID-19 - China. Accessed July 31, 2021. https://www.who.int/emergencies/diseaseoutbreak-news/item/2020-DON229

2. Halpin DMG, Faner R, Sibila O, Badia JR, Agusti A. Do chronic respiratory diseases or their treatment affect the risk of SARS-CoV-2 infection? Lancet Respir Med. 2020;8(5):436438. doi:10.1016/S2213-2600(20)30167-3

3. Wu C, Zheng S, Chen Y, Zheng M. Single-cell RNA expression profiling of ACE2, the putative receptor of Wuhan 2019nCoV, in the nasal tissue. medRxiv. Preprint posted online February 18, 2020. doi:10.1101/2020.02.11.20022228

4. Wark PAB, Pathinayake PS, Kaiko G, et al. ACE2 expression is elevated in airway epithelial cells from older and male healthy individuals but reduced in asthma. Respirology. 2021;26(5):442-451. doi:10.1111/resp.14003

5. Peters MC, Sajuthi S, Deford P, et al. COVID-19-related Genes in Sputum Cells in Asthma. Relationship to Demographic Features and Corticosteroids. Am J Respir Crit Care Med. 2020;202(1):8390. doi:10.1164/rccm.202003-08210C erratum in...

6. Sajuthi SP, DeFord P, Jackson ND, et al. Type 2 and interferon inflammation strongly regulate SARS-CoV-2 related gene expression in the airway epithelium. bioRxiv. Preprint posted online April 10, 2020. doi:10.1101/2020.04.09.034454

7. 2021 GINA Report, Global Strategy for Asthma Management and Prevention. Global Initiative for Asthma. 2021. Accessed July 31, 2021. https://ginasthma.org/gina-reports/

8. Antonicelli L, Tontini C, Manzotti G, et al. Severe asthma in adults does not significantly affect the outcome of COVID-19 disease: Results from the Italian Severe Asthma Registry. Allergy. 2021;76(3):902-905. doi:10.1111/all.14558

9. Guo W, Li M, Dong Y, et al. Diabetes is a risk factor for the progression and prognosis of COVID-19. Diabetes Metab Res Rev. 2020;36(7):e3319. doi:10.1002/dmrr.3319

10. Patrucco F, Benfante A, Villa E, Principe S, Scichilone N, Solidoro P. Severe asthma and COVID-19: lessons from the first wave. J Asthma. 2020;1-7. doi:10.1080/02770903.2020.1861622

11. People with Moderate to Severe Asthma. Centers for Disease Control and Prevention. Updated April 7, 2021. Accessed July 31, 2021. https://www.cdc.gov/coronavirus/2019-ncov/ need-extra-precautions/asthma.html

12. Matsumoto K, Saito $H$. Does asthma affect morbidity or severity of COVID-19? J Allergy Clin Immunol. 2020;146(1):55-57. doi:10.1016/j.jaci.2020.05.017

13. Li X, Xu S, Yu M, et al. Risk factors for severity and mortality in adult COVID-19 inpatients in Wuhan. J Allergy Clin Immunol. 2020;146(1):110-118. doi:10.1016/j.jaci.2020.04.006

14. Hartmann-Boyce J, Gunnell J, Drake J, et al. Asthma and COVID-19: review of evidence on risks and management considerations. BMJ Evid Based Med. 2020;26(4):195. doi:10.1136/bmjebm-2020-111506

15. Skevaki C, Karsonova A, Karaulov A, Xie M, Renz H. Asthma-associated risk for COVID-19 development. J Allergy Clin Immunol. 2020;146(6):1295-1301. doi:10.1016/j.jaci.2020.09.017

16. Broadhurst R, Peterson R, Wisnivesky JP, et al. Asthma in COVID-19 Hospitalizations: An Overestimated Risk Factor? Ann Am Thorac Soc. 2020;17(12):1645-1648. doi:10.1513/AnnalsATS.202006-613RL

17. Bousquet J, Jutel M, Akdis CA, et al. ARIA-EAACl statement on asthma and COVID-19 (June 2, 2020). Allergy. 2021;76(3):689-697. doi:10.1111/all.14471

18. Izquierdo JL, Almonacid C, González Y, et al. The impact of COVID-19 on patients with asthma. Eur Respir J. 2021;57(3):2003142. doi:10.1183/13993003.03142-2020

19. Beurnier A, Jutant EM, Jevnikar M, et al. Characteristics and outcomes of asthmatic patients with COVID-19 pneumonia who require hospitalisation. Eur Respir J. 2020;56(5):2001875. doi:10.1183/13993003.01875-2020

20. Williamson EJ, Walker AJ, Bhaskaran K, et al. Factors associated with COVID-19-related death using OpenSAFELY. Nature. 2020;584(7821):430-436. doi:10.1038/s41586-020-2521-4

21. Borobia AM, Carcas AJ, Arnalich F, et al. A Cohort of Patients with COVID-19 in a Major Teaching Hospital in Europe. J Clin Med. 2020;9(6):1733. doi:10.3390/jcm9061733

22. Rezende LFM, Thome B, Schveitzer MC, Souza-Júnior PRB, Szwarcwald CL. Adults at high-risk of severe coronavirus disease-2019 (Covid-19) in Brazil. Rev Saude Publica. 
2020;54:50. doi:10.11606/s1518-8787.2020054002596

23. Shabrawishi M, Al-Gethamy MM, Naser AY, et al. Clinical, radiological and therapeutic characteristics of patients with COVID-19 in Saudi Arabia. PLoS One. 2020;15(8):e0237130. doi:10.1371/journal.pone.0237130

24. Onder G, Rezza G, Brusaferro S. Case-Fatality Rate and Characteristics of Patients Dying in Relation to COVID-19 in Italy. JAMA. 2020;323(18):1775-1776. doi:10.1001/jama.2020.4683

25. Regina J, Papadimitriou-Olivgeris M, Burger R, et al. Epidemiology, risk factors and clinical course of SARSCoV-2 infected patients in a Swiss university hospital: An observational retrospective study. PLoS One. 2020;15(11):e0240781. doi:10.1371/journal.pone.0240781

26. Bloom Cl, Drake TM, Docherty AB, et al. Risk of adverse outcomes in patients with underlying respiratory conditions admitted to hospital with COVID-19: a national, multicentre prospective cohort study using the ISARIC WHO Clinical Characterisation Protocol UK. Lancet Respir Med. 2021;9(7):699-711. doi:10.1016/S2213-2600(21)00013-8

27. García-Moguel I, Díaz Campos R, Alonso Charterina S, Fernández Rodríguez C, Fernández Crespo J. COVID-19, severe asthma, and biologics. Ann Allergy Asthma Immunol. 2020;125(3):357-359.e1. doi:10.1016/j.anai.2020.06.012

28. Renner A, Marth K, Patocka K, Pohl W. COVID-19 in a severe eosinophilic asthmatic receiving benralizumab - a case study. J Asthma. 2021;58(9):1270-1272. doi:10.1080/02770903.2020.1781165

29. Lommatzsch M, Stoll P, Virchow JC. COVID-19 in a patient with severe asthma treated with Omalizumab. Allergy. 2020;75(10):2705-2708. doi:10.1111/all.14456

30. Çakmak ME, Kaya SB, Bostan ÖC, et al. Mortality due to COVID-19 in a Patient with Severe Asthma Receiving Omalizumab Treatment: A Case Report. Asthma Allergy Immunology. 2020;18(Suppl 1):27-29. doi:10.21911/aai.584

31. Hanon S, Brusselle G, Deschampheleire M, et al. COVID-19 and biologics in severe asthma: data from the Belgian Severe Asthma Registry. Eur Respir J. 2020;56(6):2002857. doi:10.1183/13993003.02857-2020

32. Rial MJ, Valverde M, Del Pozo V, et al. Clinical characteristics in 545 patients with severe asthma on biological treatment during the COVID-19 outbreak. J Allergy Clin Immunol Pract. 2021;9(1):487-489.e1. doi:10.1016/j.jaip.2020.09.050

33. Haroun-Díaz E, Vázquez de la Torre M, Ruano FJ, et al. Severe asthma during the COVID-19 pandemic: Clinical observations. J Allergy Clin Immunol Pract. 2020;8(8):2787-2789. doi:10.1016/j.jaip.2020.06.033

34. Abdelmaksoud A, Goldust M, Vestita M. Omalizumab and COVID-19 treatment: Could it help? Dermatol Ther. 2020;33(4):e13792. doi:10.1111/dth.13792

35. Zhang JJ, Dong X, Cao YY, et al. Clinical characteristics of 140 patients infected with SARS-CoV-2 in Wuhan, China. Allergy. 2020;75(7):1730-1741. doi:10.1111/all.14238 